\title{
Drug Exposure via Breast Milk
}

National Cancer Institute

\section{Source}

National Cancer Institute. Drug Exposure via Breast Milk. NCI Thesaurus. Code C117311.

Ingestion of drugs contained in breast milk. 